Article

\title{
A Study on the External Stone Cladding System in Production and Installation Stages: The Case of Hong Kong
}

\author{
Chun Fai Yiu ${ }^{1}$, Yoo-Jun Kim ${ }^{2}$, WoonSeong Jeong ${ }^{3}{ }^{\mathbb{D}}$, Hung-Lin Chi ${ }^{1}$ and Min-Koo Kim ${ }^{3, *}$ \\ 1 Department of Building and Real Estate, Hong Kong Polytechnic University, Hong Kong, China; \\ alvin.yiu@connect.polyu.hk (C.F.Y.); hung-lin.chi@polyu.edu.hk (H.-L.C.) \\ 2 School of Civil, Architectural Engineering and Landscape Architecture, Sungkyunkwan University, \\ Seobu-ro, Jangan-gu, Suwon-si, Gyeonggi-do 16419, Korea; yooun@skku.edu \\ 3 Department of Architectural Engineering, Chungbuk National University, Chungdae-ro 1, \\ Seowon-gu, Cheongju, Chungbuk 28644, Korea; wsjeong@chungbuk.ac.kr \\ * Correspondence: joekim@chungbuk.ac.kr
}

Received: 14 September 2020; Accepted: 12 November 2020; Published: 19 November 2020

\begin{abstract}
The successful quality management of the external stone cladding system in production and installation stages is of vital importance to ensure the high quality of the completed system. Nevertheless, little research has been conducted in this area. This research aimed to report the current status of the external stone cladding system in the production and installation stages in Hong Kong. To do so, this paper examines its current practices and major issues occurred through case studies, questionnaire surveys, and interviews. The results revealed the insufficiency in control mechanism and quality control in the system in Hong Kong. Furthermore, the factors to ensure the quality of the two stages were determined. Lastly, this research suggested recommendations on the possible measures to improve the system quality: pre-testing of stone materials and anchorage system, quality assurance of suppliers and manufacturers, regular inspections and audits on production, and continuous site quality supervision and checklist. The findings and outcomes of the research could lead to actions to guarantee steady quality for the stone cladding façade.
\end{abstract}

Keywords: stone cladding; production and installation stages; quality control; Hong Kong

\section{Introduction}

External stone cladding is made use of a thin stone panel affixed to building surfaces enclosing the building structures as architectural decoration added to the external building facades [1]. It is usually installed on the building structures through mechanical anchorage systems or direct application of cement-based materials on its rear surface to a structural substrate. As a stone is a natural substance with inherent variability, its properties differ considerably between different type, colors, grades, and cutting direction, as well as even the stones of the same type, color, and bed processed from the same quarry [2]. Therefore, stone cladding needs due consideration in its unique characteristics and performance [3]. The previous studies revealed the defects and deficiencies in the completed external stone cladding systems which required the building owners to pay huge amount of money for the remedial works [4-6].

Many studies have focused on the solutions in response to the encountered problems at different stages of the external stone cladding system. In the design stage, the knowledge gap between architects and engineers was one of the leading causes of cladding failures. Developing design standards and engineering guidelines was recommended to narrow the knowledge gap [7]. Ref. [8] also suggested the ten steps of design procedures to minimize unnecessary failures due to poor design and methods. In the 
maintenance stage, ref. [9] studied causes of stone decay and suggested preventive treatments through an overview of the previous researches on stone conservation. Additionally, a study by [10] developed service life prediction models for external stone cladding which allows more rational management of the maintenance of a building. However, relatively little research has been reported for the production stage and installation stage, particularly lacking the current status and important factors related to production and installation quality of the external stone cladding system in Hong Kong.

This study concerns the definition of the production stage as a process of transformation of material into the final product after its design stage. It is the last stage until the factory is ready to deliver the tailor-made stone panels for site installation. The installation stage in this study is defined as the last phase of external stone cladding work before its completion and proceeding towards its maintenance stage. The case studies described in Section 2.2. showed the partial problems (e.g., substandard stone materials; surface defects and misalignment; and cracking and damage during transportation) occurred on the external stone cladding system in the two stages in Hong Kong. In this regard, the research objectives of this study are:

- To identify the current status of the external stone cladding system in the two stages.

- To analyze the major factors at the stages affecting the performance of the stone cladding system.

- To suggest recommendations to alleviate the quality control of the system in the two stages.

\section{Background}

\subsection{Development of Application of External Stone Cladding System in Hong Kong}

The evolution of stone cladding facades closely parallels to the modernism of building construction and technologies [3]. The innovation of curtain wall framework was a milestone in the natural stone façade system. Stone cladding panels were then enabled to be mounted in horizontal strips for spandrel panels or vertical bands for column coverings. Different anchorage methods were also designed to hold the stone panels within the curtain walls and independent stone cladding system. Ref. [3] also pointed out that skyscrapers, built during that time, accelerated the development of stone facades using thin stone veneers substantially. Without the growing need of the height increment, natural stones could stay bulky, thick and close to their applications in the ancient monuments. Owing to the rise of the post-modern architectural style and introduction of the new natural stone block cutting and manufacturing technology in the late 1970s, the stone industry could produce thin stone panels from $30 \mathrm{~mm}$ to $40 \mathrm{~mm}$ thick. The increased resurgence and economic competitiveness of stones have made them broadly and continuously utilized in the past several decades as a cladding material for dressing building façades.

In Hong Kong, external stone cladding systems were mainly used in commercial developments, including office and hotel projects in the 1980s. The majority of stone cladding systems were installed at a lower portion of the external building walls, as well as interior entrance lobbies and halls of the buildings [11]. Granite with the polished finish was commonly adopted as the stone cladding materials [12]. At that period, most of the stone panels were imported from the foreign countries in Europe and North and South American. As a result, the construction cost of the stone cladding system was much higher than other alternative materials, such as paint and tile. Therefore, it was rarely applied in other developments, such as residential and industrial, where their primary function needed was habitation and manufacture rather than aesthetic value. Since the late 20th century, the open-market policies implemented in Mainland China has pushed the rapid development of China's stone supply and production markets to cater for local and export demands. The mature and stable of stone products made in China lowered the overall construction cost of the stone cladding system steadily, which in turn increased its competitive advantages to enhance its application in Hong Kong. Meanwhile, the expanding economy of Hong Kong has dramatically improved the quality of people's life [13]. The tone cladding system offers unique significant aesthetics, sense of elegance and permanence, and has provided an incentive for the building developers to use the stone cladding 
system in order to increase the attractiveness of their development and satisfy the expectations of end-users. Today, it is usual to observe that an external stone cladding has been installed to various kinds of building developments and renovations, such as private residential and educational projects.

\subsection{Issues of External Stone Cladding System in Production and Installation Stages Revealed by Case Studies}

In Hong Kong, the current status of the external stone cladding system in production and installation stages is a relatively blind spot. On the contrary to the other stages, such as design stage and maintenance stage, there are lack of previous studies have been reported in the production or installation stage. To identify the status in the stages, the data of two projects completed in Hong Kong were analyzed. Brief information of two chosen projects is summarized in Table 1.

Table 1. Information on two projects selected for case studies.

\begin{tabular}{lllcccc}
\hline & $\begin{array}{c}\text { Type or } \\
\text { Project }\end{array}$ & Location & Type of Work & $\begin{array}{c}\text { Stone } \\
\text { Material }\end{array}$ & $\begin{array}{c}\text { Applied } \\
\text { Façade Area }\end{array}$ & Failures \\
\hline Project 1 & Commercial & Wan Chai & $\begin{array}{c}\text { Alteration \& } \\
\text { Addition }\end{array}$ & Granite & 16/F to 24/F & $\begin{array}{c}\text { Falls caused by } \\
\text { spalls and cracks }\end{array}$ \\
\hline Project 2 & Residential & To Kwa Wan & New Building & Granite & Podium & Spalls and cracks \\
\hline
\end{tabular}

Information and data of the two projects located in Hong Kong were received from one of the interviewees participated in both questionnaire survey and face-to-face interviews. The case studies revealed that the two projects experienced similar difficulties on the quality control on the external stone cladding system in the two stages. These include substandard stone materials; surface defects and misalignment; and cracking and damage during transportation. These problems are further discussed below.

\subsubsection{Substandard Stone Materials}

Criteria of the granite cladding system and the materials were also listed out in the approved drawings. The project architect approved the principle contractor sublet all granite cladding work to one subcontractor and his granite samples. These granite samples were then sent to an accredited laboratory to perform the initial strength tests. However, some samples failed the tests of both flexural strength and anchorage stress, as well as significant variations, were observed in the test results. Another batch of samples from the same stone supplier in Mainland China was re-tested, but similar results were obtained. It was evident that the granite materials provided by the supplier contained inherent defects and variabilities that led the samples to fail in the tests with considerable inconsistency. Given this reason, the principal contractor engaged another supplier and visited the storehouse to select the granite panels. All selected granite panel eventually passed the laboratory tests including flexural strength and anchorage stress tests, but the principle contractor had to bear part of the extra cost incurred in the substitution of the substandard granite materials.

\subsubsection{Surface Defects and Misalignment}

In a site inspection, the construction manager discovered that some edges of the completed stone cladding were irregular and have indentations, particular the edges interfacing with the curtain wall system and at the corners of wall openings like windows, louvres and doors. Besides, alignment and layout of the whole completed stone façade deviated from the drawings approved by the designers and the Buildings Department. The problems may be due to the shoddy workmanship arose from cutting the stone panels on-site to accommodate the as-built dimensions of finished structures and other façade components. As a result, some stone panels with apparent irregularity and indentations were replaced, and the amendment plan was also submitted to the Buildings Department. 


\subsubsection{Cracking and Damage during Transportation}

Once the fabricated stone panels were delivered from the production factory in Mainland China to the construction site in Hong Kong, the stone installers opened the package boxes. They found that some panels had cracks or were broken, which constituted approximate $2 \%$ of the total ordered amount. As observed, the fabricated stone panels were secured and separated by thin wooden battens. However, some battens were also ruptured so the insufficiently protected stone panels could not withstand the impact loads induced during their transportation from Mainland China to Hong Kong. As a result, it took four weeks to check and replace all the damaged stone panels.

\section{Methodology}

To achieve the proposed research objectives, this research study was divided into three main stages: research design, data collection, and data analysis and discussion, as shown in Figure 1.

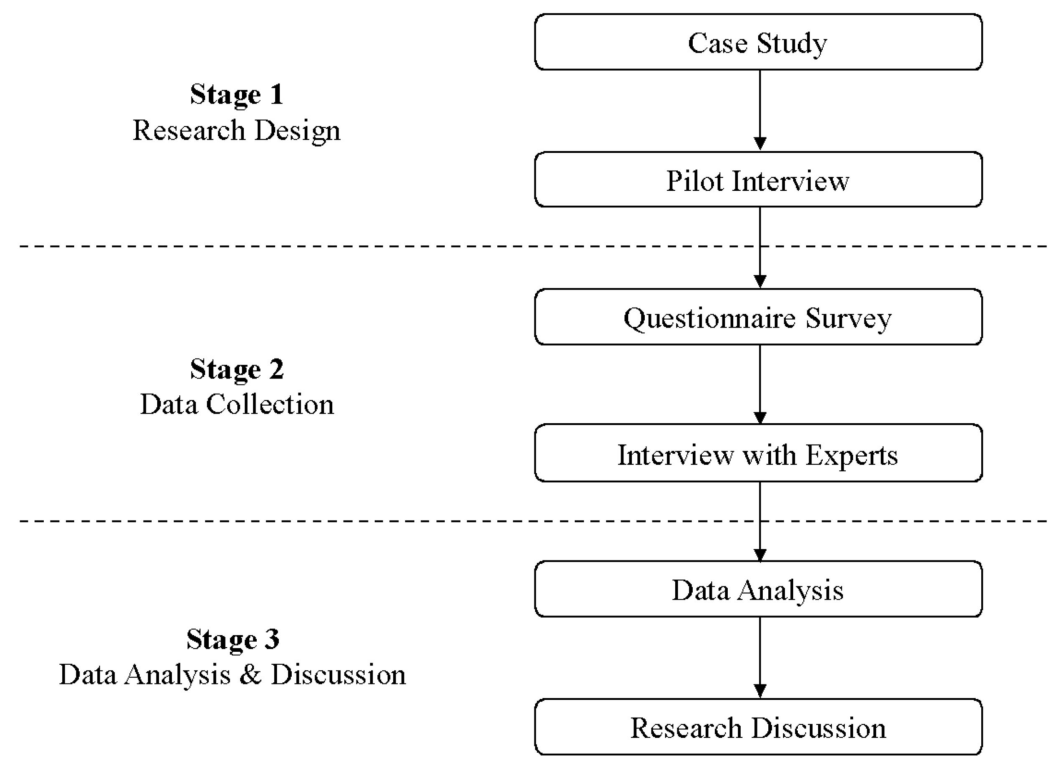

Figure 1. Research flow chart.

A questionnaire method was introduced in this research to obtain valuable opinions on the local industry practices and current statutory control mechanism of the external stone cladding system at the two stages: production stage and installation stage. From the background knowledge and critical issues reviewed from the case studies, a questionnaire was devised and created. Furthermore, pilot interviews were conducted with two building professionals to refine and finalize the questionnaire before it was released. The questionnaire was structured into three sections: (1) adequateness of statutory control and monitoring mechanism of the external stone cladding system, (2) factors to ensure the quality in the production stage, and (3) factors to ensure the quality in the installation stage. In the survey, the respondents had to make a decent score on a scale from the lowest $(+1)$ to the highest level $(+5)$ against each variable using a five-point Likert scale. The questionnaire was distributed by emails to 358 building-related companies and practitioners in Hong Kong. The questionnaire survey replies were provided by 53 respondents, representing a response rate of $14.8 \%$. The groups of respondents were found to be Contractors (17 responses, 32.1\%), Civil/Geotechnical/Structural Engineers (14 responses, 26.4\%), Architects (12 responses, 22.6\%), and Building/Quantity Surveyors (10 responses, $18.9 \%$ ). The majority of the respondents had more than 10 years of experience in the construction industry, where 11 to 15 -year is $28.3 \%, 16$ to 20 -year is $18.9 \%$, and over 20 years is $15.1 \%$.

Since the respondents may have varied perspectives depending on their workgroup, several statistical tests were further introduced to find out any significant differences in the level of importance rated by the workgroups. The data obtained from the respondents were grouped into two types, 
responses from the design team and the construction team, based on their main perspectives for design or construction aspects of the external stone cladding system. The design team included civil/geotechnical/structural engineers, architects, and building surveyors, while the construction team consisted of contractors, subcontractors, and building engineers. Quantity surveyors, representing aspects of neither design nor construction solely, were not included in both groups. The approach and procedures used to conduct statistic tests for two independent groups were formulated and are shown in Figure 2.

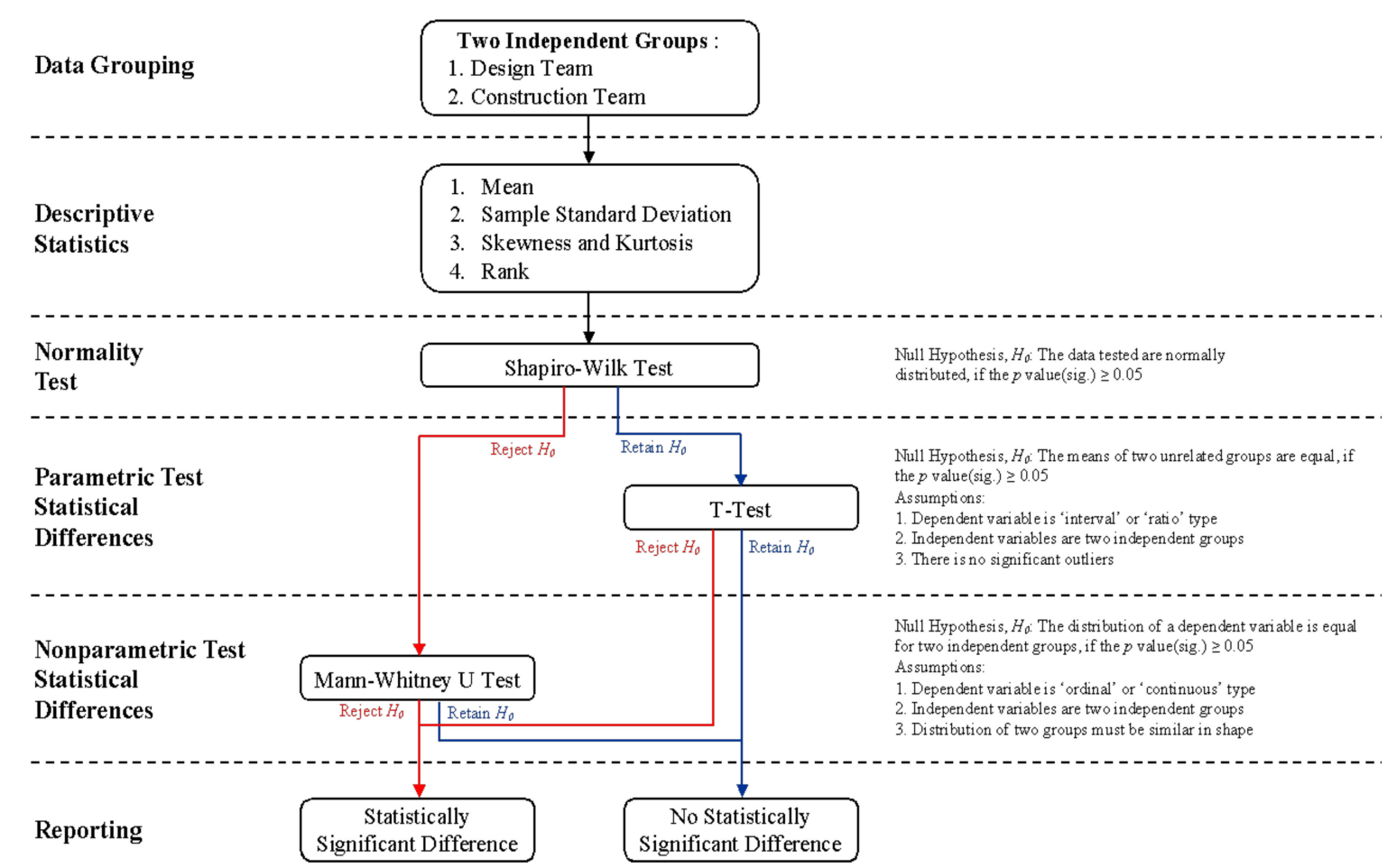

Figure 2. Flow chart of the adopted statistical tests for two independent groups.

Shapiro-Wilk test is used in this study for a normality assessment of data. The normality assessment of data is a prerequisite for some statistic tests, as the normal distribution of a variable is an underlying criterion when the parametric test is used. 'Anderson-Darling' [14], 'Kolmogorov-Smimov' [15], and 'Shapiro-Wilk' [16] are the normality test commonly adopted to determine the statistical data if a variable in a population is normally distributed. It is claimed that 'Shapiro-Wilk' test has higher statistical power than others for a given significance [17]. The null-hypothesis (H0) of the Shapiro-Wilk test is that the data tested is typically distributed in the population. If the value of $p$ (sig.) is more significant than 0.05 , the data is considered to be a normally distributed population in this research study. The test statistic is calculated as below.

$$
W=\frac{\left(\sum_{i=1}^{n} a_{i} x_{(i)}\right)^{2}}{\sum_{i=1}^{n}\left(x_{i}-\bar{x}\right)^{2}}
$$

where

$x_{(i)}=$ sample mean, and

$\bar{x}=i^{\text {th }}$ order statistic.

The Mann-Whitney $U$ test, also known as the Wilcoxon rank-sum test, was conducted in this study for a non-parametric variable to compare if there was a statistical difference between two independent. It has better statistical power than the independent-sample t-test as alterative if the assumption of a 
normal distribution for a variable in each group is violated or any outliers are present [18]. $U$ statistic is acquired by the following equation.

$$
U_{1}=R_{1}-\frac{n_{1}\left(n_{1}+1\right)}{2}
$$

where

$n_{1}=$ sample size for sample 1 , and

$R_{1}=$ sum of the ranks in sample 1 .

Therefore,

$$
U_{1}+U_{2}=R_{1}-\frac{n_{1}\left(n_{1}+1\right)}{2}+R_{2}-\frac{n_{2}\left(n_{2}+1\right)}{2} .
$$

Furthermore, the interviews were carried out by meeting with several professionals to complement the information provided by the questionnaire survey. The surveys were focused on their opinions and advice for the possible improvements to the local practices that could be applied to the production stage and installation stage of external stone cladding systems in Hong Kong. Four experienced professionals who also engaged in the questionnaire survey attended the interviews. The workgroups of the professionals included an architect, a structural engineer, a construction manager, and a subcontractor, each with more than 15 years of experience. They were interviewed face-to-face separately. A list of questions based on the results and findings obtained from the case studies and the questionnaire survey was prepared. The questions were semi-structured so that the interviewees could add their questions and comments. The survey systematically obtained their views and recommendations on how to improve the current practices and deficiencies of local stone claddings in the production stage and installation stage. The data collected in each interview was analyzed to allow cross-validation of data with the case studies and the questionnaire survey.

\section{Results}

\subsection{Statutory Control and Monitoring Mechanism of the External Stone Cladding System in Hong Kong}

As presented in Figure 3, nominated subcontractor/specialist contractor (49.7\%) and main contractor (35.0\%) were the parties who usually undertook the design responsibilities of the external stone cladding system and prepared the statutory submissions. Figure 4 represents that the majority of the respondents (42.3\%) expressed their neutral comment on the inadequacy of present statutory mechanism on the external stone cladding system, and $32.7 \%$ and $7.7 \%$ of the respondents agreed or strongly agreed with the statement, which were higher than the responses in 'disagree $(15.4 \%)^{\prime}$ and 'strongly disagree $(1.9 \%)^{\text {' }}$. Table 2 shows the statistical difference in the statement between the two groups. Since the null hypothesis for the normality was rejected, non-parametric tests for statistical comparison differences were used. For two independent groups, the design team rated the degree of agreement more strongly than the construction team $(U=89, p=0.000)$.

The interview survey results also corroborate the dissimilar statements on the statutory control and monitoring requirements. The construction manager and the site agent expressed similar views that the present statutory requirements on the external stone cladding system are sufficient to ensure its quality. On the other hand, the architect and the registered structural engineer stood for 'insufficient' and 'very insufficient' on the question statement, respectively. They claimed that no catastrophic consequences happened in Hong Kong because the defects and failures of the completed external stone cladding systems were addressed and rectified before the problems became apparent and led to severe accidents. The leading causes of the problems encountered are the inadequate quality control performed for the production process. For the tempered glass used in curtain wall or glass wall systems and precast concrete construction, a quality assurance scheme of the manufacturer should be submitted before the application of consent to its work. In addition, technically competent persons should 
be assigned to supervise the production works in the factory according to their required frequent inspection. During their inspections, they should also record the details of production, inspection, auditing, and testing in a logbook. Therefore, the architect and the registered structural engineer suggested that similar approaches adopted in curtain wall and structural precast concrete elements may be applied to the external stone cladding system. Mainly, stone panels should be manufactured by a factory with quality assurance certification and close control and supervision by the technically competent persons in the production stage in manufacturer's factory.

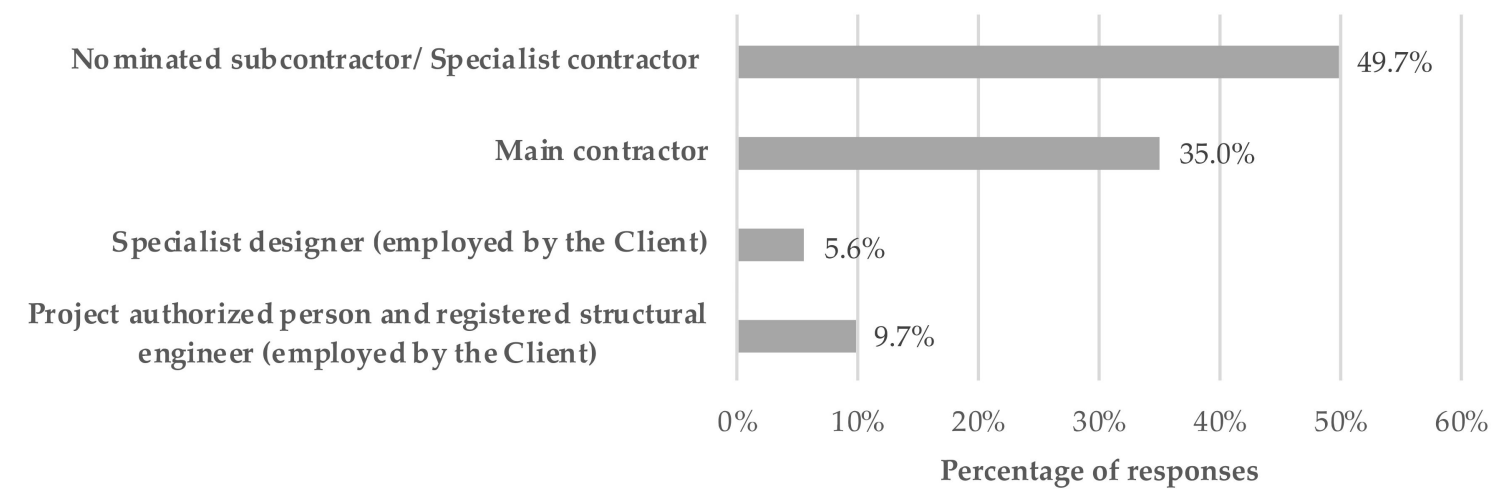

Figure 3. Percentage of project parties who undertake the design responsibilities of the external stone cladding system and prepared the statutory submissions in private projects $(n=53)$.

Comment on the statement of "Statutory control and monitoring requirements in HK on external stone cladding system are relatively loose compared with other external façade systems"

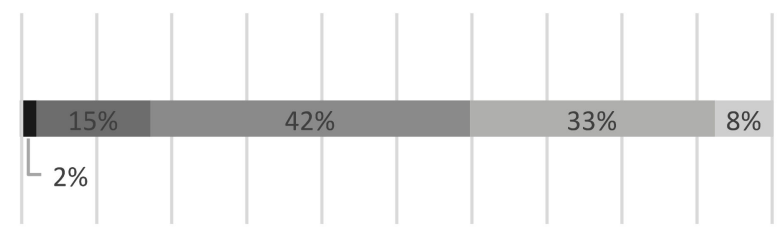

$\begin{array}{llllllllllll}0 \% & 10 \% & 20 \% & 30 \% & 40 \% & 50 \% & 60 \% & 70 \% & 80 \% & 90 \% & 100 \%\end{array}$

Percentage of responses

Figure 4. Comment on the statement of "Statutory control and monitoring requirements in Hong Kong on the external stone cladding system are relatively loose compared with other external façade systems" $(n=53)$.

\subsection{Factors to Ensure the Quality in the Production Stage of the External Stone Cladding System in Hong Kong}

Figure 5 shows that the primary source of stone supply and production of the stone cladding panels for private building projects in Hong Kong was mainland china constituted the estimated percentage of $76.7 \%$ and $88.8 \%$, respectively. Total percentage of supply and production by Hong Kong and other foreign countries was about $23 \%$ and $11 \%$ only.

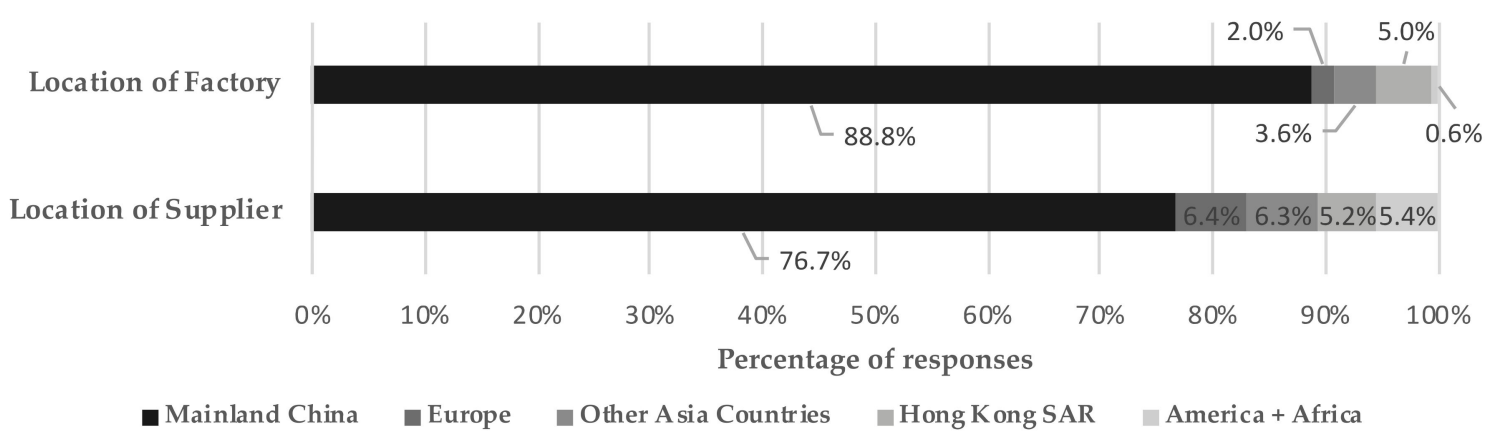

Figure 5. Location of supplier/factory of the stone block for private building projects in HK $(n=53)$. 
During production stage of stone materials, as shown in Figure 6, majority of the respondents visited the supplier's storehouse 1 3 times (43.4\%) and 4 6 times (30.1\%) to choose the stone raw material for their building projects. At the production stage, the majority of the respondents conducted their inspections at $1 \sim 3$ times $(66.0 \%)$ and $4 \sim 6$ times $(15.1 \%)$. The respondents did not carry out a visit at the production stage $(17 \%)$ and the production stage $(11.3 \%)$. The survey results indicate that most of the respondents inspected the storehouses and factories to ensure the quality of the stone materials and cladding panels used for their projects in Hong Kong.

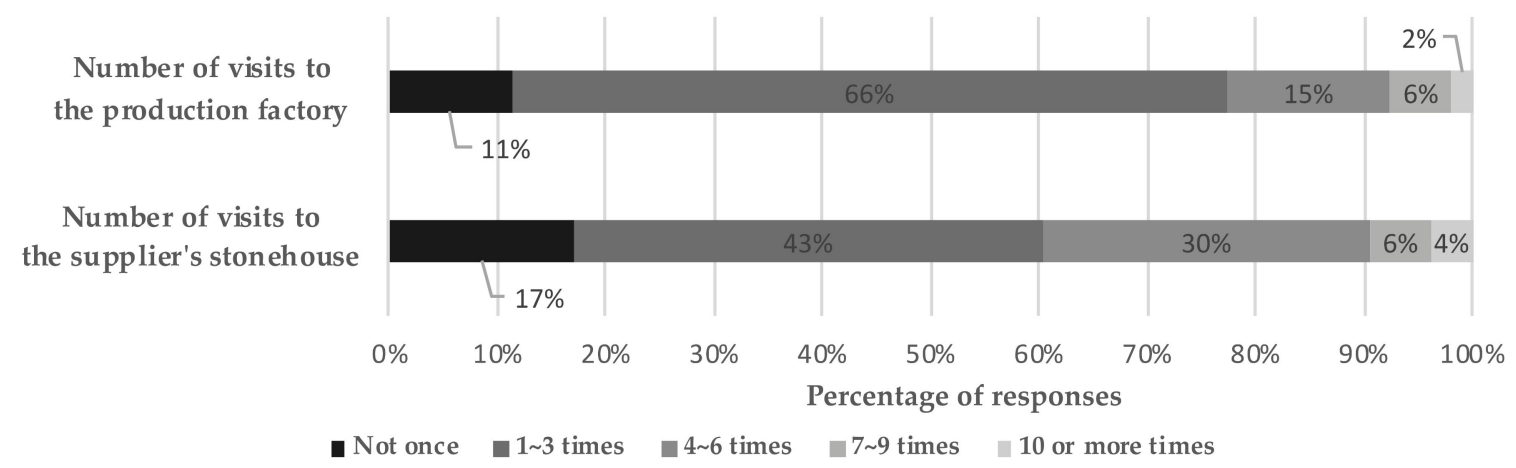

Figure 6. Number of visits to the supplier's storehouse/production factory per building project in $\mathrm{HK}(n=53)$.

As presented in Figure 7, factors that could enhance and ensure the quality in the production stage of stone cladding panels were (1) supervision by Technically Competent Persons, (2) quality assurance scheme executed by the manufacturer, (3) pre-testing (initial test) on the stone materials \& cladding system, and (4) quality assurance provided by the stone supplier. Evaluation of stone materials by an expert, such as a geologist, was considered as least important.

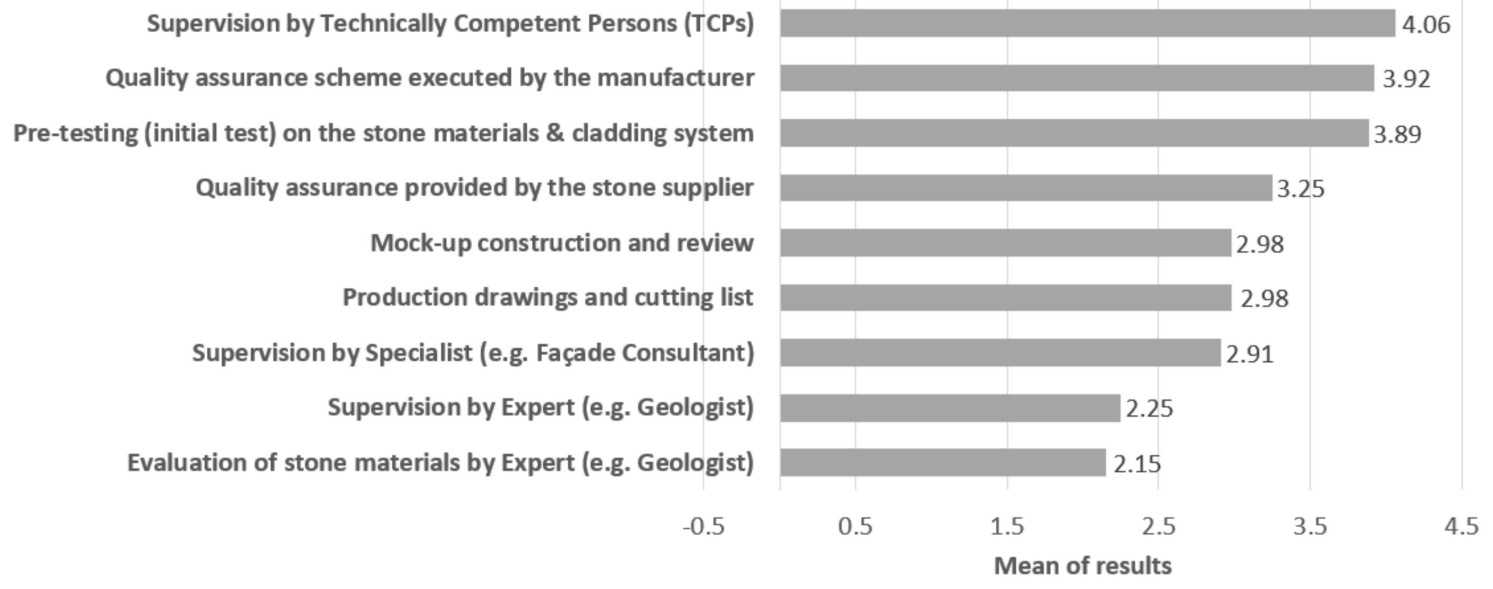

Figure 7. Factors to ensure the quality in the production stage $(n=53)$.

Table 3 represents that the statistical results from the two independent groups were similar except their ranking. The design team ranked (1) supervision by Technically Competent Persons (TCPs), (2) initial test, and (3) Quality Assessment (QA) scheme executed by the manufacturer; on the other hand, the construction team also placed (1) supervision by TCPs, (2) QA scheme executed by the manufacturer, and (3) initial test. As the dependent variables were not normally distributed, the non-parametric test of Mann-Whitney $U$ was utilized to examine the statistical differences in rating between the two groups. As a result, only the factor named mock-up construction and review was found to have a significant difference $(\mathrm{U}=163.5, p=0.010)$ among the nine factors. 
Table 2. Comment on the statement of statutory control and monitoring mechanism of the external stone cladding system are relatively loose compared with other external façade systems (Comparison between 'Design Team' and 'Construction Team', $n=50$ ).

\begin{tabular}{|c|c|c|c|c|c|c|c|c|c|c|c|c|c|c|c|}
\hline \multirow{3}{*}{ Item } & \multirow{3}{*}{ Factors } & \multicolumn{6}{|c|}{ Design Team } & \multicolumn{6}{|c|}{ Construction Team } & \multirow{2}{*}{\multicolumn{2}{|c|}{$\begin{array}{c}\text { Mann-Whitney } \\
\text { U Test }\end{array}$}} \\
\hline & & \multicolumn{4}{|c|}{ Descriptive Statistics } & \multicolumn{2}{|c|}{ Shapiro-Wilk Test } & \multicolumn{4}{|c|}{ Descriptive Statistics } & \multicolumn{2}{|c|}{ Shapiro-Wilk Test } & & \\
\hline & & $\mathbf{N}$ & Mean & SD & SK & $\mathbf{W}$ & Sig. & $\mathbf{N}$ & Mean & SD & SK & $\mathbf{W}$ & Sig. & $\mathbf{U}$ & Sig. \\
\hline 1 & $\begin{array}{c}\text { Strongly Disagree, Disagree, } \\
\text { neutral, Agree or Strongly Agree }\end{array}$ & 33 & 3.67 & 0.692 & 0.557 & 0.772 & 0.000 & 17 & 2.53 & 0.800 & 0.308 & 0.862 & 0.016 & 89.0 & 0.000 \\
\hline
\end{tabular}

Table 3. Factors to ensure the quality in the production stage (Comparison between 'Design Team' and 'Construction Team', $n=50)$.

\begin{tabular}{|c|c|c|c|c|c|c|c|c|c|c|c|c|c|c|c|}
\hline \multirow{3}{*}{ Item } & \multirow{3}{*}{ Factors } & \multicolumn{6}{|c|}{ Design Team } & \multicolumn{6}{|c|}{ Construction Team } & \multirow{2}{*}{\multicolumn{2}{|c|}{$\begin{array}{c}\text { Mann-Whitney } \\
\text { U Test }\end{array}$}} \\
\hline & & \multicolumn{4}{|c|}{ Descriptive Statistics } & \multicolumn{2}{|c|}{$\begin{array}{c}\text { Shapiro-Wilk } \\
\text { Test }\end{array}$} & \multicolumn{4}{|c|}{ Descriptive Statistics } & \multicolumn{2}{|c|}{$\begin{array}{c}\text { Shapiro-Wilk } \\
\text { Test }\end{array}$} & & \\
\hline & & $\mathbf{N}$ & Mean & SD & SK & W & Sig. & $\mathbf{N}$ & Mean & SD & SK & $\mathbf{W}$ & Sig. & $\mathbf{U}$ & Sig. \\
\hline 1 & QA provided by the stone supplier & 33 & 3.18 & 0.769 & 0.109 & 0.852 & 0.000 & 17 & 3.41 & 0.618 & 1.275 & 0.678 & 0.000 & 321.5 & 0.352 \\
\hline 2 & QA scheme executed by the manufacturer & 33 & 3.97 & 0.684 & -0.586 & 0.792 & 0.000 & 17 & 3.94 & 0.827 & 0.117 & 0.806 & 0.002 & 270.0 & 0.812 \\
\hline 3 & Pre-testing of stone materials \& system & 33 & 4.00 & 0.750 & -0.473 & 0.832 & 0.000 & 17 & 3.76 & 0.664 & 0.291 & 0.792 & 0.002 & 226.0 & 0.218 \\
\hline 4 & Production drawings and cutting list & 33 & 2.91 & 0.723 & 0.668 & 0.804 & 0.000 & 17 & 3.06 & 0.659 & -0.057 & 0.798 & 0.002 & 318.5 & 0.380 \\
\hline 5 & Mock-up construction and review & 33 & 3.12 & 0.696 & -0.168 & 0.803 & 0.000 & 17 & 2.59 & 0.870 & 1.629 & 0.710 & 0.000 & 163.5 & 0.010 \\
\hline 6 & Evaluation of stone materials by experts & 33 & 2.15 & 0.795 & 0.905 & 0.777 & 0.000 & 17 & 2.12 & 0.781 & -0.219 & 0.812 & 0.003 & 286.5 & 0.891 \\
\hline 7 & Supervision by TCP & 33 & 4.12 & 0.600 & -0.038 & 0.761 & 0.000 & 17 & 3.94 & 0.659 & 0.057 & 0.798 & 0.002 & 240.0 & 0.337 \\
\hline 8 & Supervision by Specialist & 33 & 2.91 & 0.522 & -0.139 & 0.697 & 0.000 & 17 & 2.82 & 0.636 & 0.143 & 0.785 & 0.001 & 258.0 & 0.575 \\
\hline 9 & Supervision by Expert & 33 & 2.21 & 0.650 & 1.949 & 0.540 & 0.000 & 17 & 2.29 & 0.686 & 0.861 & 0.779 & 0.001 & 307.5 & 0.460 \\
\hline
\end{tabular}


In the interview survey, four interviewees agreed that Mainland China has turned into the primary source of stone suppliers and fabricators. Since the reformation and opening-up of China's market, the stone industry has been steadily developed in China. Today, the China's stone production bases are mainly Yunfu in Guangdong, Laizhou in Shandong, and Quanzhou in Fujian, among which Yunfu is constructing a world's largest international stone industrial city. However, the architect, the registered structural engineer, and the construction manager commented that the stone suppliers and factories in China vary greatly in their scale, quality, and reliability. Therefore, the visit of the storehouses and factories of the proposed stone suppliers and fabricators is vitally important to verify their capabilities and performance in quality control and assurance on their materials and production process. Besides, the stone suppliers and fabricators should have the International Organization for Standardization quality assurance certificates (ISO9000) to ensure that they are continuously performing quality management system and achieving the required quality standard. During the production process of stone panels, regular inspections and audits should be conducted by the representatives of the client, such as the project architect and structural engineer, as well as the independent agency of the client, to secure the fulfilment of legal and contractual requirements and specifications. Inspection and audit reports should also be prepared periodically to monitor the quality and progress of stone panel production and treatment.

\subsection{Factors to Ensure the Quality in the Installation Stage of the External Stone Cladding System in Hong Kong}

With respect to the critical success factors for the external stone cladding installation in Hong Kong, Figure 8 presents that the most critical factors were (1) monitoring and inspection on the production process in a factory until all stone panels are delivered, (2) skilled installer, (3) qualified/continuous site supervision by TCPs, and (4) material and technical specifications. Referring to the results grouped by 'Design Team' or 'Construction Team' for the installation stage in Table 4, the first three critical success factors, chosen by the design team and construction team, were not identical; the former selected (1) material and technical specifications, (2) qualified/continuous site supervision by TCPs, and (3) monitoring and inspection on the production process in a factory until all stone panels are delivered, but the latter ranked (1) monitoring and inspection on production process, (2) skilled labors, (3) protection for delivery, and (4) qualified/continuous site supervision by TCPs. Since the normality assumption of the dependent variables could not be met, the Mann-Whitney $U$ test was applied instead of independent-samples T-test. It was found that the median of material and technical specifications rated by the groups of the design team was significantly higher than that of the construction team $(U=155$, $p=0.004)$. On the other hand, the median of protection for the delivery of stone panels rated by the groups of the design team was significantly lower than that of construction $(\mathrm{U}=418.5, p=0.002)$.

The interview survey results were adduced to explain the outcomes of the questionnaire survey. The architect believed that the specifications and skilled installers are crucial to the successful installation of external stone cladding in Hong Kong. The material and technical specifications are essential written contract documents that are legally binding and used to specify the minimum requirements of submissions, control samples, materials, workmanship, testing, etc. Comprehensive specifications could, therefore, form a common basis for all project parties to verify the quality and performance of the stone cladding work, as well as eliminate any substandard materials and works. He also pointed out that site works of external cladding system involve intensive labor force to install drilled-in anchors, anchorage brackets, stone cladding panels, and apply epoxy grout. As necessary, the formation of anchorage slots or holes and touch-up treatment on stone cladding panels may be carried out on-site in place of in the production factory to suit the as-built conditions and alignment of substrates for fixing. Thus, skill and experience of the local installers significantly affect the performance of the system in terms of its aesthetic quality, durability, resistance to external effects and loads due to wind, temperature, and chemical, etc. Only registered skilled workers and semi-skilled workers of designated stone cladding trade should be appointed to carry out site installation works. 
On-site control mock-ups may also be constructed to review the critical connection and interfacing details of the system and the acceptable standard of works.

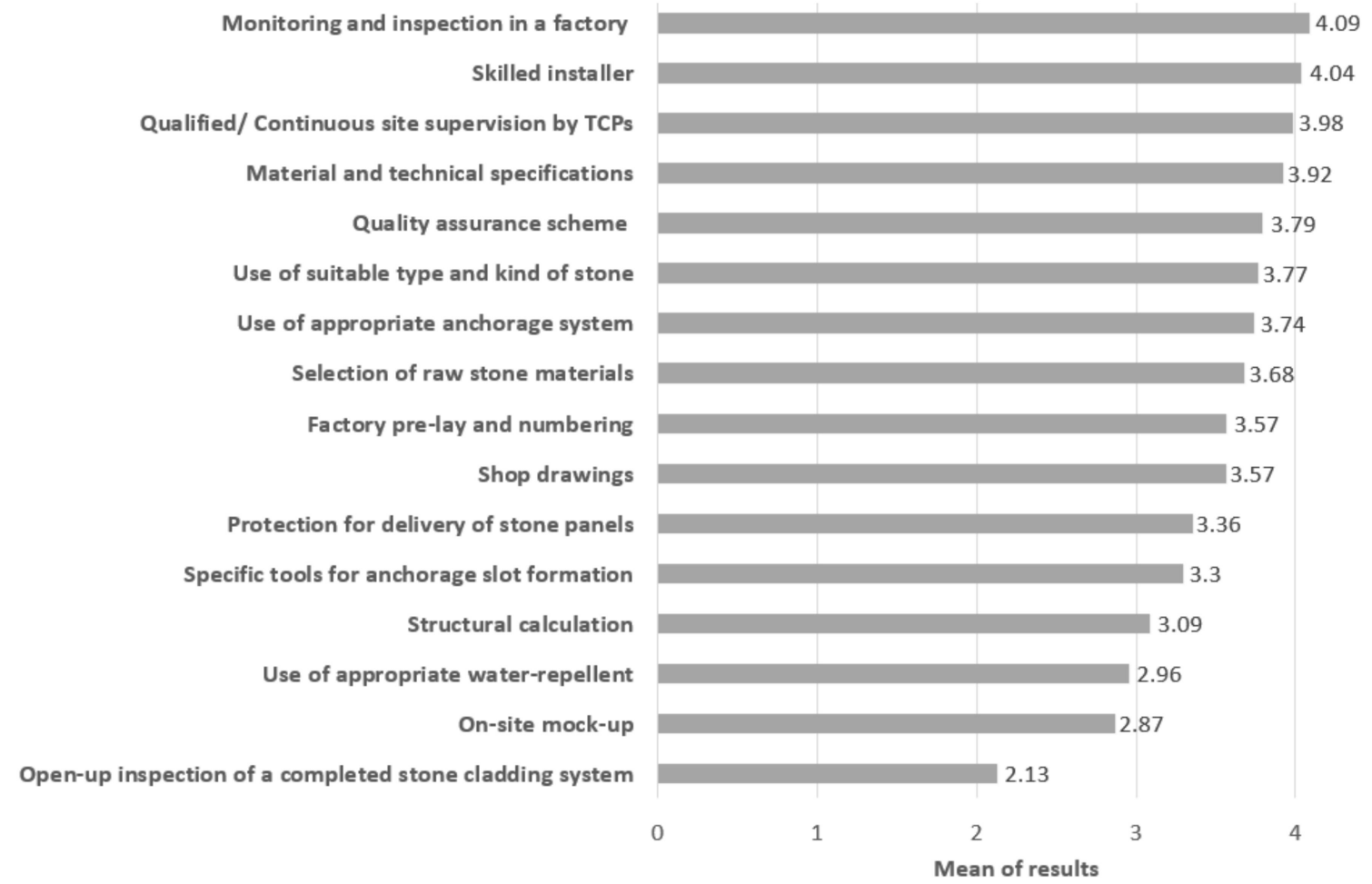

Figure 8. Factors that are crucial to the successful installation of the external stone cladding system and minimize its defects in HK $(n=53)$.

The registered structural engineer and the construction manager advised that site supervision of external stone cladding works should also be strengthened on top of the appointment of skilled installers. As reiterated in the Practice Note for Authorized Persons APP-158 issued by the Building Authority in November 2016, the registered building professionals have the duties to conduct supervision the building works being carried out, and the registered contractor should also provide continuous supervision therein. Therefore, qualified and continuous supervised should be implemented by the assigned technically competent persons to reinforce the control and monitoring of on-site stone cladding installation works. Inspection schedule and a checklist for this specific work-trade should also be devised to facilitate the site inspection process and ensure the checking on all essential items regularly and systematically. It needs to be updated to suit the actual site works and operations, as well as changes in site conditions. They suggested that the checklist should include those items in Table 5. 
Table 4. Factors to ensure the quality in the installation stage (Comparison between 'Design Team' and 'Construction Team', $n=50)$.

\begin{tabular}{|c|c|c|c|c|c|c|c|c|c|c|c|c|c|c|c|}
\hline \multirow{3}{*}{ Item } & \multirow{3}{*}{ Factors } & \multicolumn{7}{|c|}{ Design Team } & \multicolumn{5}{|c|}{ Construction Team } & \multirow{2}{*}{\multicolumn{2}{|c|}{$\begin{array}{l}\text { Mann-Whitney } \\
\text { U Test }\end{array}$}} \\
\hline & & \multicolumn{4}{|c|}{ Descriptive Statistics } & \multicolumn{3}{|c|}{$\begin{array}{l}\text { Shapiro-Wilk } \\
\text { Test }\end{array}$} & \multicolumn{3}{|c|}{ Descriptive Statistics } & \multicolumn{2}{|c|}{$\begin{array}{l}\text { Shapiro-Wilk } \\
\text { Test }\end{array}$} & & \\
\hline & & $\mathbf{N}$ & Mean & SD & SK & $\mathbf{W}$ & Sig. & $\mathbf{N}$ & Mean & SD & SK & $\mathbf{W}$ & Sig. & $\mathbf{U}$ & Sig. \\
\hline 1 & Material \& technical specifications & 33 & 4.09 & 0.631 & -0.066 & 0.780 & 0.000 & 17 & 3.53 & 0.514 & -0.310 & 0.642 & 0.000 & 155.0 & 0.004 \\
\hline 2 & $\begin{array}{l}\text { QA provided by the } \\
\text { supplier/manufacturer/subcontractor }\end{array}$ & 33 & 3.82 & 0.635 & -0.618 & 0.768 & 0.000 & 17 & 3.71 & 0.588 & 0.109 & 0.750 & 0.000 & 248.5 & 0.440 \\
\hline 3 & Shop drawings & 33 & 3.52 & 0.566 & -0.614 & 0.703 & 0.000 & 17 & 3.76 & 0.562 & -0.083 & 0.733 & 0.000 & 337.0 & 0.182 \\
\hline 4 & Structural calculation & 33 & 3.12 & 0.740 & 0.293 & 0.840 & 0.000 & 17 & 3.12 & 0.485 & 0.399 & 0.659 & 0.000 & 282.0 & 0.972 \\
\hline 5 & Use of suitable type and kind of stone & 33 & 3.76 & 0.435 & -1.260 & 0.534 & 0.000 & 17 & 3.82 & 0.636 & 0.143 & 0.785 & 0.001 & 291.0 & 0.788 \\
\hline 6 & Selection of raw stone materials & 33 & 3.61 & 0.864 & -0.349 & 0.862 & 0.000 & 17 & 3.82 & 0.728 & 0.290 & 0.809 & 0.003 & 312.0 & 0.487 \\
\hline 7 & Use of appropriate anchorage system & 33 & 3.76 & 0.614 & -0.684 & 0.753 & 0.000 & 17 & 3.76 & 0.664 & 0.291 & 0.792 & 0.002 & 274.0 & 0.877 \\
\hline 8 & Monitoring \& inspection during production & 33 & 4.03 & 0.637 & -0.023 & 0.784 & 0.000 & 17 & 4.29 & 0.686 & -0.456 & 0.789 & 0.001 & 340.5 & 0.169 \\
\hline 9 & Factory pre-lay and numbering & 33 & 2.48 & 0.619 & 0.061 & 0.785 & 0.000 & 17 & 2.71 & 0.59 & 0.109 & 0.75 & 0.000 & 331.5 & 0.240 \\
\hline 10 & Protection for delivery of stone panels & 33 & 3.12 & 0.650 & -0.118 & 0.788 & 0.000 & 17 & 3.88 & 0.78 & 0.219 & 0.812 & 0.003 & 418.5 & 0.002 \\
\hline 11 & On-site mock-up & 33 & 2.91 & 0.522 & -0.139 & 0.697 & 0.000 & 17 & 2.76 & 0.75 & 1.433 & 0.709 & 0.000 & 231.0 & 0.216 \\
\hline 12 & Skilled installer & 33 & 4.00 & 0.500 & 0.000 & 0.675 & 0.000 & 17 & 4.18 & 0.73 & -0.290 & 0.809 & 0.003 & 324.0 & 0.288 \\
\hline 13 & Specific tools for anchorage slot formation & 33 & 3.27 & 0.626 & 0.551 & 0.771 & 0.000 & 17 & 3.41 & 0.51 & 0.394 & 0.632 & 0.000 & 317.5 & 0.375 \\
\hline 14 & Qualified site supervision by TCPs & 33 & 4.06 & 0.496 & 0.153 & 0.67 & 0.000 & 17 & 3.88 & 0.49 & -0.399 & 0.659 & 0.000 & 236.5 & 0.228 \\
\hline 15 & Open-up inspection of completed stone cladding & 33 & 2.15 & 0.755 & 0.200 & 0.848 & 0.000 & 17 & 2.00 & 0.79 & 0.000 & 0.817 & 0.003 & 254.0 & 0.558 \\
\hline 16 & Use of appropriate water repellant & 33 & 2.97 & 0.810 & -0.696 & 0.827 & 0.000 & 17 & 2.94 & 0.56 & -0.051 & 0.732 & 0.000 & 263.5 & 0.692 \\
\hline 17 & Periodic site inspection by Expert & 33 & 2.15 & 0.795 & 0.905 & 0.777 & 0.000 & 17 & 2.24 & 0.83 & 0.243 & 0.877 & 0.029 & 303.0 & 0.605 \\
\hline
\end{tabular}


Table 5. Proposed items in the checklist for external stone cladding installation.

\begin{tabular}{cl}
\hline Item & \multicolumn{1}{c}{ Necessary Checking } \\
\hline Substrate & As-built alignment, size, strength, quality, defects \\
\hline Waterproofing on substrate & Workmanship, coverage, thickness \\
\hline Drill-in anchors & $\begin{array}{l}\text { Type and model, amount, layout, delivery records, material certificates, } \\
\text { pull-out test reports }\end{array}$ \\
\hline Anchorage brackets & $\begin{array}{l}\text { Type, size, thickness, amount, layout, delivery records, mill certificates, } \\
\text { strength test reports }\end{array}$ \\
\hline Stone cladding panels & $\begin{array}{l}\text { Type, dimensions, thickness, color, surface finish, water-repellent, anchorage } \\
\text { slots/holes, alignment, defects, flexural strength reports, aging test reports }\end{array}$ \\
\hline Adhesive grout & Type, location, delivery records, adequacy, workmanship, storage \\
\hline Sealant & Type, width, thickness, location, delivery records, workmanship, storage \\
\hline
\end{tabular}

\section{Discussion and Conclusions}

This paper presents the current status of the external stone cladding system in the production and installation stages in Hong Kong. The results from the case studies, questionnaire survey, and interviews offer valuable insights regarding the system at the two stages. First, around $40 \%$ of respondents believed that the current control mechanism is insufficient compared with other external façade systems (in Figure 4). Second, the stone suppliers and factories mostly from Mainland China (in Figure 5) vary significantly in their scale and quality. The quality management, supervision by TCPs, quality assurance scheme by the manufacturer, and initial test should be considered to enhance the quality control at the production stages (in Figure 7). Third, close supervision and periodic inspection during production and delivery are essential for successful installation stage of the system (in Figure 8). Lastly, the varied perspectives depending on their workgroup are confirmed. For the statement on the inadequacy of the present statutory control mechanism, the design team expressed their degree of agreement much stronger than the construction team (in Table 2). Furthermore, the design team rated the factor' material and technical specifications' significantly higher $(U=155, p=0.004)$, while 'protection for the delivery of stone panel' much lower than that of the construction team. The lack of mutual understandings between workgroups was considered as one of the most detrimental factors against the supply chain management implementation in Hong Kong (Wong et al., 2004). Therefore, it is worth studying the differences in detail among the workgroups of the external stone cladding system in future research. Based on the results and findings of this study, the possible measures to improve and enhance the quality and performance of the external stone cladding system are recommended as follows:

1. Pre-testing of stone materials and anchorage system should be performed to ensure the required standards specified in the contract and legislation in the production stage.

2. Quality assurance should be executed in the supply chain and production process so that its end products can consistently meet the specified quality and performance standards.

3. Regular inspections and audits in the production stage are highly recommended. Besides, having technically competent persons of the consultant team and contractors is suggested to perform this task and record the findings in logbooks.

4. Continuous quality supervision should be conducted on-site, and a comprehensive checklist should be devised for control and monitoring on quality of works during the installation stage.

Despite the fact that this study conducted the systemized research methods, the research scope and objectivity might be limited. The number of variables, case projects, and interviewees may be insufficient to reflect an overall view of the situation in Hong Kong. Other variables, such as types of clients [19,20], stone types [2,21], and project characteristics [20,22], may have substantial effects on the quality performance in the construction industry. In line with this study, further studies complementing 
these stated limitations will materialize in-depth understanding of characteristics of the external stone cladding system in the production and installation stages.

Author Contributions: C.F.Y. conceived the idea for this study and wrote the manuscript. Y.-J.K. conceived the idea and revised the manuscript. H.-L.C. supervised the research and revised the manuscript. W.J. conceived some ideas and revised the paper. M.-K.K. supervised and edited the paper. All authors have read and agreed to the published version of the manuscript.

Funding: This research was supported by the Basic Science Research Program through the National Research Foundation of Korea (NRF) funded by the Ministry of Education (2020R1I1A3052594). This research was also supported by Chungbuk National University Korea National University Development Project (2020).

Conflicts of Interest: The authors declare no conflict of interest.

\section{References}

1. Hall, K. Natural building stone composed of light-transmissive minerals: Impacts on thermal gradients, weathering and microbial colonization. A preliminary study, tentative interpretations, and future directions. Environ. Earth Sci. 2011, 62, 289-297. [CrossRef]

2. Yu, J.Y.H.; Chan, S.L. Practice and Testing of Stone Cladding in Hong Kong; Department of Civil and Structural Engineering, The Hong Kong Polytechnic University: Hong Kong, China, 2006.

3. Lewis, M.D. Modern Stone Cladding: Design and Installation of Exterior Dimension Stone Systems; ASTM: West Conshohocken, PA, USA, 1995.

4. Solinski, J.P. Thin Stone Veneer/Study and Remediation. In Dimension Stone Cladding: Design, Construction, Evaluation and Repair; ASTM International: West Conshohocken, PA, USA, 2000.

5. Neto, N.; Brito, J.D. Validation of an inspection and diagnosis system for anomalies in natural stone cladding. Constr. Build. Mater. 2012, 30, 224-236. [CrossRef]

6. Camposinhos, R.S. Undercut anchorage in dimension stone cladding. Proc. Inst. Civ. Eng. Constr. Mater. 2013, 166, 158-174. [CrossRef]

7. Cohen, J.M. Cladding design: Whose responsibility? J. Perf. Constr. Fac. ASCE 1991, 5, 208-218. [CrossRef]

8. Faddy, M.J.; Wilson, R.J.; Winer, G.M. The Determination of the Design Strength of Granite Used as External Cladding for Buildings. In Case Studies in Reliability and Maintenance; John Wiley \& Son, Inc.: Hoboken, NJ, USA, 2003; pp. 111-134.

9. Doehne, E.; Price, C.A. Stone Conservation. An Overview of Current Research; The Getty Conservation Institute: Los Angeles, CA, USA, 2010.

10. Silva, A.; Dias, J.; Gaspar, P.; Brito, J. Service life prediction models for exterior stone cladding. Build. Res. Inf. 2011, 39, 637-653. [CrossRef]

11. Haase, M.; Amato, A. A study of the effectiveness of different control strategies in double skin facades in warm and humid climates. J. Build. Perform. Simul. 2009, 2, 179-187. [CrossRef]

12. Rui, D.D.S.C. Stone Cladding Engineering; Springer: Dordrecht, The Netherlands, 2014.

13. Chiu, R.L.H. Social equity in housing in the Hong Kong special administrative region: A social sustainability perspective. Sustain. Dev. 2002, 10, 155-162. [CrossRef]

14. Anderson, T.W.; Darling, D.A. Asymptotic Theory of Certain Goodness of Fit Criteria Based on Stochastic Processes. Ann. Math. Stat. 1952, 23, 193-212. [CrossRef]

15. Kolmogorov, A. Über die analytischen Methoden in der Wahrscheinlichkeitsrechnung. Math. Ann. 1931, 104, 415-458. [CrossRef]

16. Shapiro, S.S.; Wilk, M.B. An analysis of variance test for normality (complete samples). Biometrika 1965, 52, 591-611. [CrossRef]

17. Razali, N.M.; Wah, Y.B. Power comparisons of Shapiro-Wilk. Kolmogorov-Smirnov 2011, Lilliefors and Anderson-Darling tests. J. Stat. Modell. Anal. 2011, 2, 21-33.

18. Mann, H.B.; Whitney, D.R. On a test of whether one of two random variables is stochastically larger than the other. Ann. Math. Stat. 1947, 18, 50-60. [CrossRef]

19. Naoum, S.G.; Mustapha, F.H. Influences of the client designer and procurement method on project performance. In Proceedings of the CIB W92 Symposium “East Meets West”, Hong Kong, China, 4-7 December 1994; pp. 221-228. 
20. Chan, P.C.; Tam, C.M. Factors affecting the quality of building projects in Hong Kong. Int. J. Qual. Reliab. Manag. 2000, 17, 423-442. [CrossRef]

21. Naggatz, S.G.; Gerns, E.A. Full-scale flexural strength testing for stone cladding design. In Dimension Stone Cladding: Design, Construction, Evaluation, and Repair; Hoigard, K.R., Scheffler, M.J., Eds.; American Society for Testing and Materials: West Conshohocken, PA, USA, 2007; pp. 3-10.

22. Walker, D.H.T. An Investigation into Factors That Determine Building Construction Time Performance. Ph.D. Thesis, Royal Melbourne Institute of Technology, Melbourne, Australia, 1994.

Publisher's Note: MDPI stays neutral with regard to jurisdictional claims in published maps and institutional affiliations.

(C) 2020 by the authors. Licensee MDPI, Basel, Switzerland. This article is an open access article distributed under the terms and conditions of the Creative Commons Attribution (CC BY) license (http://creativecommons.org/licenses/by/4.0/). 